\title{
Combined replacements of the wrist, ulnar head, and thumb carpometacarpal joint. Case report, technical note and recent evidence to the $\mathrm{Arpe}^{\mathrm{TM}}$ prosthesis
}

Ingo Schmidt ${ }^{*}$

${ }^{1}$ SRH Poliklinik Gera GmbH, Straße des Friedens 122, 07548 Gera, Germany

\begin{abstract}
Abbreviations
OA: osteoarthritis; TWR: total wrist replacement; UHR: ulnar head replacement; TCMJ: thumb carpometacarpal joint; LRTI: ligament reconstruction and tendon interposition; UHMWPE: ultra-high molecular weight polyethylene.
\end{abstract}

Number of References: 53 (85\% not older than 10 years / 73.3\% of them not older than 5 years with a total of $62.3 \%$ ).

\section{Case presentation}

A 55-year-old male presented with right primary pancarpal wrist joint osteoarthritis (OA), accompanied with distinctive OA of the distal radioulnar joint that led to marked loss of the forearm supination-pronation motion arc (Figure 1A-B). The patient sustained primarily a total wrist replacement (TWR) accompanied with a distal ulna hemiresection (Bowers procedure) (Figure 2A-B). Three years after primary surgery, a secondary ulnar head replacement (UHR) had to be performed due to painful convergence instability of the distal ulna stump (Figure 2C). It has been previously reported in 2015 by the author on this patient with a satisfactory outcome at a 5-year follow-up [1,2]. Six months after that, the patient developed painful distinctive right thumb carpometacarpal joint (TCMJ) OA with marked loss of thumb's circumduction and restriction of tip-totip pinch. Radiographically, the screw for fixation of the carpal TWR component into the 2 nd metacarpal bone did not alter the trapez bone, and so the total TCMJ replacement using the Arpe ${ }^{\mathrm{TM}}$ implant (Biomet, Warsaw, Indiana/USA) could be performed (Figure 3A-B). One year total TCMJ replacement, there was unchanged correct positioning of all 3 implants without any signs of loosening or subsidence, but sigmoid notch erosion and bone resorption around the collar of UHR was seen (Figure 4). Bone resorption around the collar of the $\mathrm{uHead}^{\mathrm{TM}}$ implant (such as in our case) has been observed in up to $90 \%$ of cases with an average ratio of $7 \%$ ( $0-18 \%$, Bone Resorption Index) and/or sigmoid notch erosion in up to $30 \%$ of cases with an average ratio of 1.8 (1.42.6, Sigmoid Notch Erosion Index) without loosening or subsidence of the UHR [3]. It seems to be a constant phenomenon related to stress shielding around the uHead ${ }^{\mathrm{TM}}$ implant, it occurs within the first postoperative year, then stabilized to an average follow-up of 3 years [3]. Also, there was an excellent restoration of thumb's functionality with a sufficient abduction and circumduction to perform a powerful tip-to-tip pinch to the 5th finger, and in comparison to the previously published 5-year follow-up an unchanged complete restoration of forearm supination-pronation motion arc (Figure 5A-B). In order to preserve motion, the patient reported that he would undergo the same 3 replacements a second time were it necessary.
Biomechanically, TCMJ is best described as a "twisted saddle" with 2 axes for extension-flexion and abduction-adduction only, and there are several volar and especially the major strong dorsal ligaments which provide joint stability. Thumb's circumduction that requires a "third functioning axis" for pronatoric rotation (i.e. opposition), is
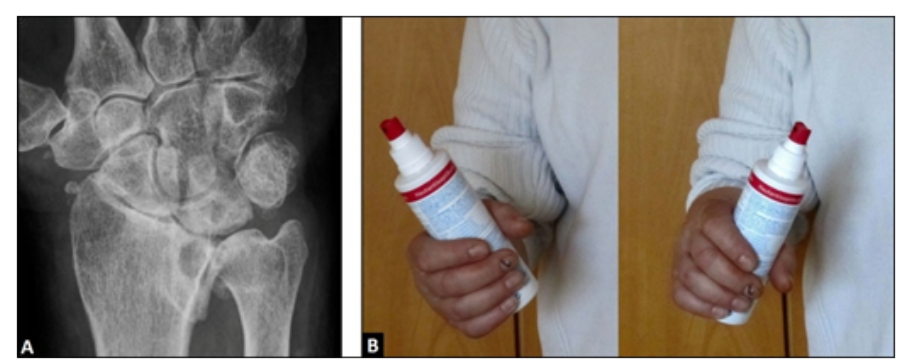

Figure 1. (Case Presentation, initial findings): (A) Postero-anterior radiograph showing right distinctive compromised wrist with pancarpal and distal radioulnar joint OA; (B) Clinical photographs demonstrating marked loss of the right forearm supination-pronation motion arc.
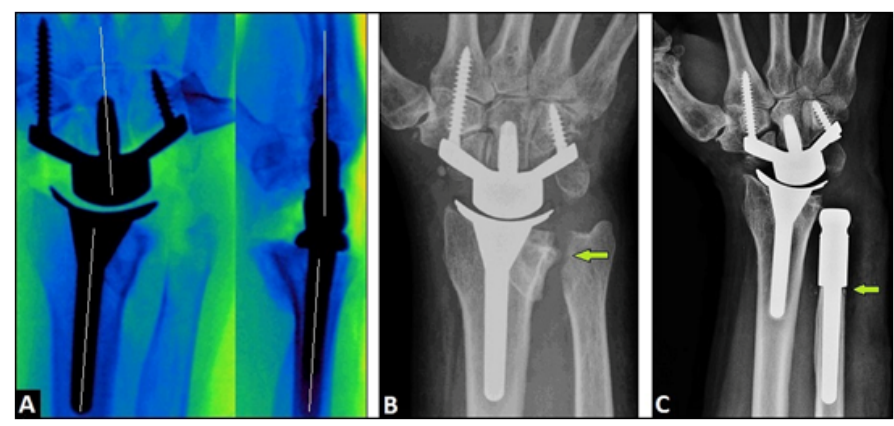

Figure 2. (Case Presentation, primary course): (A) Intraoperative fluoroscopy in both planes showing correct alignment of both TWR components along the radius shaft axis and along the capitate-3rd metacarpal bone axis (lines); (B) Postoperative postero-anterior radiograph showing correct positioning of TWR, and the Bowers procedure (arrow); (C) Postero-anterior radiograph demonstrating primary TWR combined with the secondary UHR, note that the UHR has a complete support onto the ulna shaft (arrow).

Correspondence to: Ingo Schmidt, SRH Poliklinik Gera GmbH, Straße des Friedens 122, 07548 Gera, Germany, Tel: 00491789503035; E-mail: schmidtingo62@googlemail.com

Key words: total wrist replacement, ulnar head replacement, total thumb carpometacarpal joint replacement

Received: March 12, 2017; Accepted: March 30, 2017; Published: April 01, 2017 


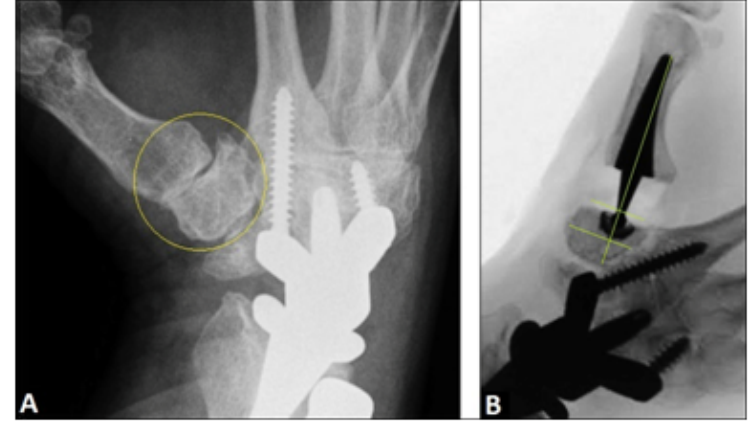

Figure 3. (Case Presentation, 6 months after the 5-year follow-up): (A) Oblique radiograph showing advanced stage of right TCMJ OA, note that the screw for fixation of the carpal TWR component into the 2nd metacarpal bone does not alter the trapez bone (arrow); (B) Intraoperative fluoroscopy showing correct positioning of the Arpe ${ }^{\mathrm{TM}}$ prosthesis with correct alignment of the cup which is parallel to the articular surface of trapez bone (lines).

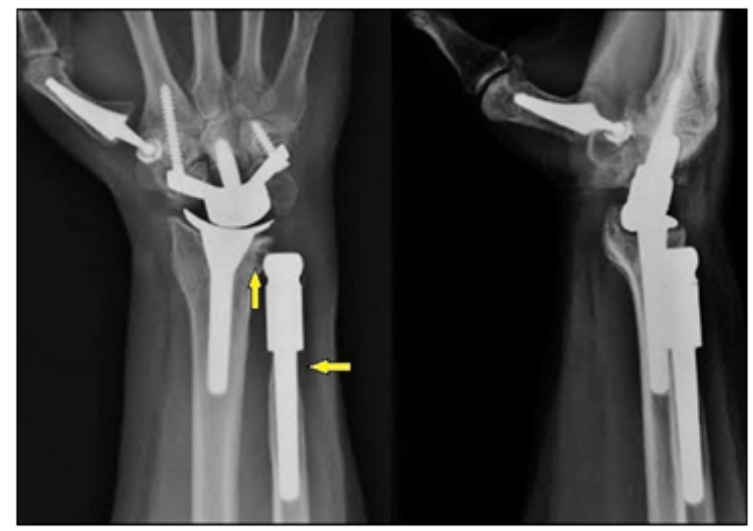

Figure 4. (Case Presentation, 1 year after total TCMJ replacement): Postero-anterior and lateral radiographs demonstrating unchanged correct positioning of TWR, UHR, and Arpe $^{\mathrm{TM}}$ prosthesis without any signs of loosening or subsidence, there is no instability of the UHR, note the bone resorption around the collar of UHR and sigmoid notch erosion 3.5 years after its insertion (arrows)
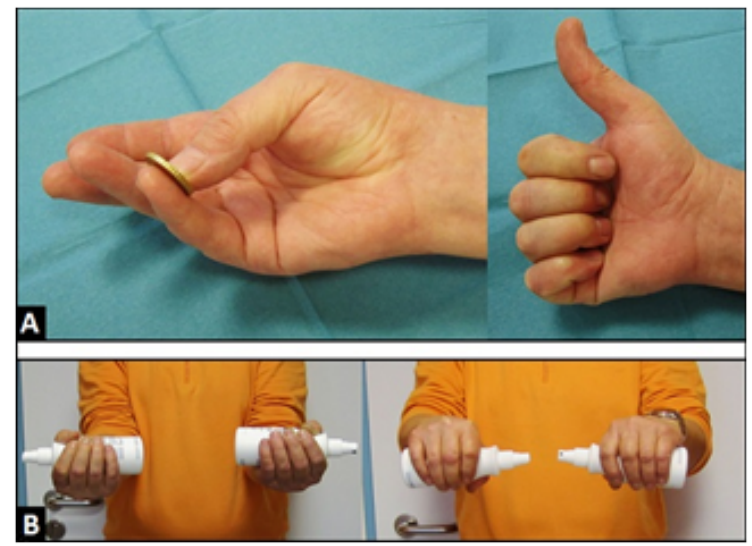

Figure 5. (Case Presentation, 1 year after total TCMJ replacement): (A) Clinical photographs demonstrating excellent restoration of thumb's functionality with sufficient circumduction to perform a powerful tip-to-tip pinch to the 5th finger, and complete extension-abduction motion arc; (B) Clinical photographs demonstrating complete restoration of forearm supination-pronation motion arc.

a result of evolution in hominid species as a functional adaption to stand upright, freeing the torso and upper limbs. Unfortunately, the great mobility that is seen in-vivo in these 3 functioning axes like a "cardan joint" makes that joint intrinsically unstable and TCMJ OA is "the price of an opposable thumb" [4]. Treatment options for TCMJ $\mathrm{OA}$ are an excisional procedure (trapeziectomy with or without ligament reconstruction and/or tendon interposition (LRTI)) that is the most frequent procedure worldwide, TCMJ arthrodesis, and total TCMJ replacement $[5,6]$. Despite recent evidence suggests that neither ligament reconstruction with tendon interposition or one of both procedures alone confers any additional benefit over trapeziectomy alone, only $3 \%$ of hand surgeons in USA performed that simpler procedure in 2010 [6-9]. The main problems of an excisional procedure are deterioration of pinch strength with time, mechanical pain related to instability or bone impingement with or without neuropathy of the superficial branch of radial nerve, high incidence of flexor carpi radialis tendinitis, and clumsiness associated with patient's trouble doing activities such as threading a needle, sewing, buttoning a blouse or shirt, turning over the pages of a newspaper, or picking up small objects $[7,8,10-16]$. It must be noted that there are not always sufficient options for surgical treatment in the future if patients are unsatisfied after an excisional procedure. Three studies revealed that a revision procedure including re-LRTI or re-suspension with the use of the mini TightRope after a failed primary excisional procedure can be associated with a complication rate up to $27 \%$, poor outcome, and incomplete pain relief [17-19]. In rheumatic patients, there is often observed a "reverse" $\mathrm{Z}$ - deformity of the thumb that presents hyperextension in TCMJ, hyperflexion in metacarpophalangeal joint, and hyperextension in interphalangeal joint of the thumb [20]. If the Z-deformity is irreducible by tightening the adductor muscle, TCMJ fusion is the surgical method of choice [21]. The "optimal treatment" for TCMJ OA would be the in-vivo transformation of biomechanically determined "cardan joint" to an intrinsically stable "ball joint" with a third central axis for pronatoric rotation to perform a powerful circumduction by an endoprosthesis. Total TCMJ replacement reduces pain, improves grip and pinch strength, and results in excellent patient's satisfaction including faster re-employment if the implants not be failed [5,6,22,23]. The main problem of total TCMJ replacement is long-term surveillance (i.e. aseptic loosening) of its cups [24]. To analyze the reasons for these high failure rates, it is necessary to explore the biomechanical imbalance across the long lever of the first metacarpal bone onto the small surface of the trapez bone, which is anatomically determined; and the different topographic load-bearing regions on the surface of trapez bone as well. A tip pinch of $1 \mathrm{~kg}$ will generate $12 \mathrm{~kg}$ joint compression; and for the power grip, the load may be as high as $120 \mathrm{~kg}$ [25]. Additionally, recent evidence suggests that cup surveillance does not depend on the preoperative radiographic staging using the classifications by Eaton-Littler (1973) or Eaton-Glickel (1987); thus, for assessment the outcome of total TCMJ replacement it has been recommended in 2015 by Larsen et al. [26] to introduce a new classification that incorporates more the preoperative patient's disability. When using non-cemented screw cups, it is also recommended to insert it without threading of the trapez bone to improve the primary insertion-related stability that is an important prerequisite for its secondary bony anchorage $[27,28]$. The question whether a press-fit non-cemented hemispherical cup is to be or is not to be preferred over a screwed non-cemented cylindrical cup remains topically unanswered. Contraindications for a noncemented total TCMJ replacement are poor bone stock, a collapsing trapez bone with a height below 11-12 mm when using the 9 or 10 $\mathrm{mm}$ in diameter Arpe ${ }^{\mathrm{TM}}$ cups, irreducible $\mathrm{Z}$ - deformity of the thumb, joint hyperlaxity, unstable soft tissue with or without infection, nerve palsies, and reduced compliance of patients. Discrete concomitant radiographic degenerative changes in scaphotrapezio-trapezoid joint without clinical manifestation appear not to be a contraindication for total TCMJ replacement [29]. Total TCMJ replacement allows additional wrist procedures such as four-corner fusion or proximal row carpectomy [30]. 

prosthesis

The Arpe ${ }^{\mathrm{TM}}$ prosthesis is one non-cemented ball-and-socket type that is currently in use [5,24]. It has a metal-on-ultra-high molecular weight polyethylene (UHMWPE) articulation, and the design resembles a "small hip prosthesis" (Figure 6). The hemispherical titanium alloy and hydroxyapatite coated cup is designed for pressfit insertion, and it has three spikes on its ground for that one invitro study demonstrated a high primary stability regarding bending strengths, and an "additional crown" could raise its stability regarding torsion strengths [31]. The titanium alloy and hydroxyapatite coated stem reproduces the anatomical shape of the first metacarpal medullary space. The problem of a ball-and-socket implant is that the central axis of cup is colinear to the axis of stem resulting in physiological load-bearing for thumb adduction only, whereas the dominant contact pattern for volar abduction and opposition is observed on the central-volar aspect of trapez bone surface [32]. To minimize the risk of loosening or dislocation, the Arpe ${ }^{\mathrm{TM}}$ cup should be placed in the centre of range of motion that is parallel to the proximal articular surface of trapez bone in the PA view (Figure 7A-C), accompanied with its angulation of $7^{\circ}$ flexion relative to the proximal surface of trapez bone in the lateral view [33]. The main disadvantage of implant is that the PE insert is fixed to the cup. Hence, in case when PE wear occurs, a revision of the entire cup becomes necessary even it may not be loosened [34]. Two comparative studies revealed that the outcomes regarding functionality and strength were better rated by patients with a total TCMJ replacement using the Arpe ${ }^{\mathrm{TM}}$ implant than by patients who underwent a primary excisional procedure $[35,36]$. At two midand one long-term follow-up's a survival rate for in-vivo functional Arpe $^{\mathrm{TM}}$ prostheses was found in $85-97 \%$ of cases $[34,37,38]$. Currently, none of all other types for total TCMJ replacements (ceramics or metal-on-metal articulation types) or TCMJ pyrocarbon interposition implants ( $\mathrm{Pi} 2$ ) revealed a survival rate of $93.9 \%$ at a 10 -year followup, and the results with the $\mathrm{Arpe}^{\mathrm{TM}}$ prosthesis are comparable with

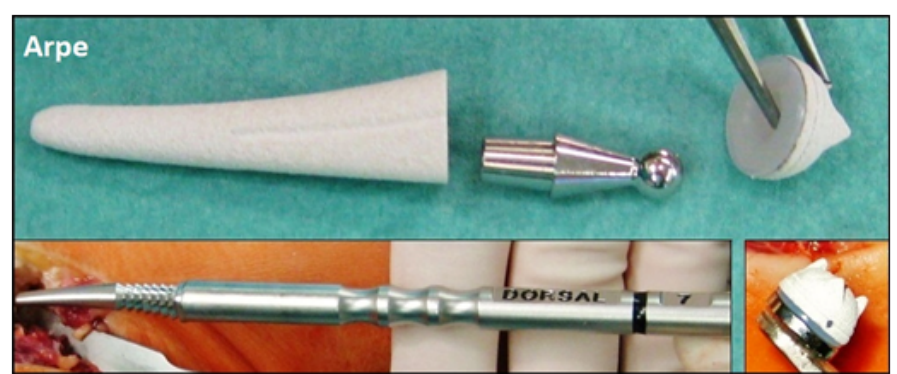

Figure 6. (Design of the $\mathrm{Arpe}^{\mathrm{TM}}$ prosthesis, collage): Three various components: the titanium alloy and hydroxyapatite coated metacarpal stem (available with sizes of 7/8/9/10) is inserted with its convex shape in dorsal direction, the titanium alloy and hydroxyapatite coated cup (available with sizes of 9 and $10 \mathrm{~mm}$ in diameter, retentive or non-retentive) has three spikes on its ground and the UHMWPE insert is fixed to the cup, the intercalated cobalt-chrome head-neck components (available with lengths of medium/large/extra-large/ extra-extra-large) are available in form of a straight or an angled design.
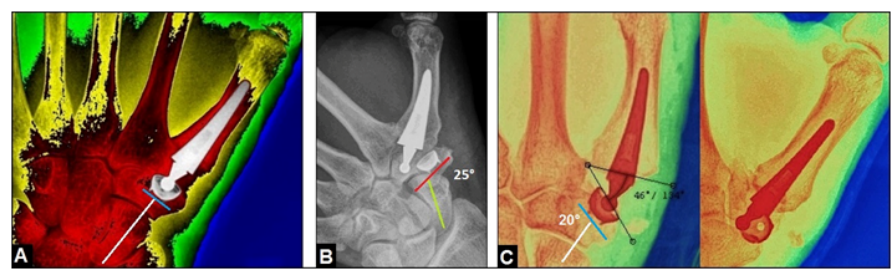

Figure 7. (Positioning of the Arpe ${ }^{\mathrm{TM}}$ cup): (A) Procedure by the author, correct alignmen of the cup parallel to the proximal articular surface of trapez bone which is usually $90^{\circ}$ angled to the central axis of scaphoid bone (lines); (B) Procedure by the author, primary misalignment of the cup with $25^{\circ}$ (lines) that led to dislocation of implant; (C) Procedure by another surgeon, primary misalignment of the cup with $20^{\circ}$ (lines) that led to its nontraumatic breakout accompanied with dislocation of implant. those of the standard reference of $93,1 \%$ in hip arthroplasty [38-42]. Regarding to the exclusively only published poor outcomes with the use of the Moje ceramic prosthesis, it has been noted by Giddins in 2012 that this implant should be withdrawn from the marketplace, but the manufacturer has not responded so far [40]. The "off-label" use of the Arpe $^{\mathrm{TM}}$ prosthesis in a "reverse manner" is reported to be critical [43]. The further development of the Arpe $^{\mathrm{TM}}$ prosthesis is the Maia ${ }^{\circ}$ prosthesis, this type has four spikes on the ground of cup to improve primary insertion-related stability, and fish-scale macrostructure at the proximal end of the stem to reduce the risk of subsidence [44]. For a failed primary total TCMJ replacement, total exchange TCMJ replacement with or without additional bone grafting, an excisional procedure with or without removal of the metacarpal stem, or TCM) arthrodesis are the salvage procedures [5,33,34,37,43,45-49]. After a failed total exchange TCMJ replacement, an excisional procedure continues to be a salvage option, the outcome of an excisional procedure after a failed total TCMJ replacement is reported to be identical to those after a primary procedure [50,51]. Based on evaluated complication rates and subjectively reported outcomes by the patients, an excisonal procedure is to be preferred primarily over TCMJ arthrodesis when both procedures are possible, especially in women aged 40 years and older [52,53].

\section{Acknowledgements}

None.

\section{Declarations}

The author declares that he has none conflict of interests concerning this article.

\section{References}

1. Schmidt I (2015) Combined replacements using the Maestro total wrist and uHead ulnar head implants. J Hand Surg Eur Vol 40: 754-755.

2. Schmidt I (2017) RE-MOTION ${ }^{\mathrm{TM}}$ total wrist arthroplasty for treatment of advanced stage of scaphoid non-union advanced collapse. Does excision of the entire scaphoid bone prevent impingement at terminal range of radial deviation? Trauma Emerg Care 2(1) $10.15761 /$ TEC. 1000127

3. Herzberg G (2010) Periprosthetic bone resorption and sigmoid notch erosion around ulnar head implants: a concern? Hand Clin 26: 573-577. [Crossref]

4. Turker T, Thirkannad S (2011) Trapezio-metacarpal arthritis: The price of an opposable thumb! Indian J Plast Surg 44: 308-316. [Crossref]

5. Schmidt I (2015) Surgical treatment options in thumb carpometacarpal osteoarthritis: recent literature overview searching for practice pattern with special focus on total joint replacement. Curr Rheumatol Rev 11: 39-46.

6. Vermeulen GM, Slijper H, Feitz R, Hovius SE, Moojen TM, et al. (2011) Surgical management of primary thumb carpometacarpal osteoarthritis: a systematic review. $J$ Hand Surg Am 36: 157-169.

7. Gangopadhyay S, McKenna H, Burke FD, Davis TR (2012) Five- to 18-year followup for treatment of trapeziometacarpal osteoarthritis: a prospective comparison of excision, tendon interposition, and ligament reconstruction and tendon interposition. J Hand Surg Am 37: 411-417.

8. Naram A, Lyons K, Rothkopf DM, Calkins ER, Breen T, et al. (2016) Increased Complications in Trapeziectomy With Ligament Reconstruction and Tendon Interposition Compared With Trapeziectomy Alone. Hand (NY) 11: 78-82.

9. Brunton LM, Wilgis EF (2010) A survey to determine current practice patterns in the surgical treatment of advanced thumb carpometacarpal osteoarthrosis. Hand (NY) 5: 415-422.

10. Yaffe MA, Butler B, Saucedo JM, Nagle DJ (2014) First carpometacarpal arthroplasty with ligamentous reconstruction: a long-term follow-up. Hand (NY) 9: 346-350.

11. Kirchberger MC, Schnabl SM, Bruckner T, Müller LP, Oppermann J, et al. (2014) Functionality of middle-aged women after resection-interposition arthroplasty of the trapeziometacarpal joint in comparison to a healthy control group. Arch Orthop Trauma Surg 134: 735-739. 
12. Klein SM, Wachter K, Koller M, Vykoukal J, Geis S, et al. (2015) Long-term results after modified Epping procedure for trapeziometacarpal osteoarthritis. Arch Orthop Trauma Surg 135: 1475-1484.

13. Cooney WP 3rd, Leddy TP, Larson DR (2006) Revision of thumb trapeziometacarpal arthroplasty. J Hand Surg Am 31: 219-227. [Crossref]

14. Megerle K, Grouls S, Germann G, Kloeters O, Hellmich S (2011) Revision surgery after trapeziometacarpal arthroplasty. Arch Orthop Trauma Surg 131: 205-210.

15. Low TH, Hales PF (2014) High incidence and treatment of flexor carpi radialis tendinitis after trapeziectomy and abductor pollicis longus suspensionplasty for basal joint arthritis. J Hand Surg Eur Vol 39: 838-844.

16. Finsen V, Wold CB, Russwurm H (2015) Clumsiness: a complication of trapeziectomy for thumb carpometacarpal joint arthritis? J Hand Surg Eur Vol 40: 326. [Crossref]

17. Renfree KJ, Dell PC (2002) Functional outcome following salvage of failed trapeziometacarpal joint arthroplasty. J Hand Surg Br 27: 96-100.

18. Sadhu A, Calfee RP, Guthrie A, Wall LB (2016) Revision Ligament Reconstruction Tendon Interposition for Trapeziometacarpal Arthritis: A Case-Control Investigation. $J$ Hand Surg Am 41: 1114-1121.

19. Szalay G, Scheufens T, Alt V, Thormann U, Heiss C (2015) Primary results using the mini TightRope for revision surgery for painful proximalisation of the first metacarpa after trapezectomy for CMC-1-osteoarthritis. Handchir Mikrochir Plast Chir 47: 1723. [Crossref]

20. Nalebuff EA (1968) Diagnosis, classification and management of rheumatoid thumb deformities. Bull Hosp Joint Dis 29: 119-137. [Crossref]

21. Teissier J, Gaudin T, Marc T (2001) Problems with the metacarpophalangeal joint in the surgical treatment of osteoarthritis by inserting an ARPE type joint prosthesis. Chir Main 20: 68-70. [Crossref]

22. Regnard PJ (2015) Moovis prosthesis for osteoarthritis of CMC joint of the tumb. BMC Proceedings 9(Suppl 3): A90

23. Dehl M, Chelli M, Lippmann S, Benaissa S, Rotari V, et al. (2017) Results of 115 Rubis II reverse thumb carpometacarpal joint prostheses with a mean follow-up of 10 years. J Hand Surg Eur Vol 2017 Feb 1:1753193416687508. doi: 10.1177/1753193416687508. [Crossref]

24. Huang K, Hollevoet N, Giddins G (2015) Thumb carpometacarpal joint tota arthroplasty: a systematic review. J Hand Surg Eur Vol 40: 338-350. [Crossref]

25. Cooney WP 3rd, Chao EY (1977) Biomechanical analysis of static forces in the thumb during hand function. J Bone Joint Surg Am 59: 27-36.

26. Larsen SK, Østergaard AM, Hansen TB (2015) The influence of subluxation on the severity of symptoms, disability, and the results of operative treatment in TMC osteoarthritis with total joint arthroplasty. Hand (NY) 10: 593-597.

27. Hansen TB, Stilling M (2013) Equally good fixation of cemented and uncemented cups in total trapeziometacarpal joint prostheses. A randomized clinical RSA study with 2-year follow-up. Acta Orthop 84: 98-105

28. Completo A, Nascimento A, Neto F (2016) Total arthroplasty of basal thumb joint with Elektra prothesis: an in vitro analysis. J Hand Surg Eur Vol 41: 930-938. [Crossref]

29. Hansen TB, Kirkeby L (2016) No correlation between severity of preoperative degenerative changes in the trapeziometacarpal joint and short-term clinical outcome after total joint arthroplasty. Hand Surg Rehabil 35: 16-20.

30. Waitzenegger T, Leclercq C, Masmejean E, Lenoir H, Harir A, et al. (2015) Combined Treatment of Wrist and Trapeziometacarpal Joint Arthritis. J Wrist Surg 4: 301-306. [Crossref]

31. Bruyère Garnier K, Dumas R, Rumelhart C, Comtet JJ (2001) Comparison of primary trapezometacarpal cup fixation using mechanical tests. Chir Main 20: 55-62. [Crossref]

32. Goto A, Leng S, Sugamoto K, Cooney WP 3rd, Kakar S, et al. (2014) In vivo pilot study evaluating the thumb carpometacarpal joint during circumduction. Clin Orthop Relat Res 472: 1106-1113. [Crossref]
33. Duerinckx J, Caekebeke P (2016) Trapezium anatomy as a radiographic reference for optimal cup orientation in total trapeziometacarpal joint arthroplasty. J Hand Surg Eur Vol 41: 939-943.

34. Eecken SV, Vanhove W, Hollevoet N (2012) Trapeziometacarpal joint replacement with the Arpe prosthesis. Acta Orthop Belg 78: 724-729. [Crossref]

35. Zanui JF, Bellés S, Sánchez MC (2006) Comparative study of surgical treatment of rhizarthrosis. Total prosthesis vs. resection arthroplasty. J Bone Joint Surg Br 88(Suppl II): 326 .

36. Martínez-Martínez F, García-Hortelano S, García-Paños JP, Moreno-Fernández JM, Martín-Ferrero MÁ (2016) Comparative clinical study of 2 surgical techniques for trapeziometacarpal osteoarthritis. Rev Esp Cir Ortop Traumatol 60: 59-66.

37. Apard T, Saint-Cast Y (2007) Results of a 5 years follow-up of Arpe prosthesis for the basal thumb osteoarthritis. Chir Main 26: 88-94. [Crossref]

38. Martin-Ferrero M (2014) Ten-year long-term results of total joint arthroplasties with ARPE $\mathbb{R}$ implant in the treatment of trapeziometacarpal osteoarthritis. J Hand Surg Eur Vol 39: 826-832. [Crossref]

39. Allami MK, Fender D, Khaw FM, Sandher DR, Esler C, et al. (2006) Outcome of Charnley total hip replacement across a single health region in England. The results at ten years from a regional arthroplasty register. J Bone Joint Surg Br 88: 1293-1298.

40. Giddins G (2012) Thumb arthroplasties. J Hand Surg Eur Vol 37: 603-604. [Crossref]

41. Frølich C, Hansen TB (2015) Complications Related to Metal-on-Metal Articulation in Trapeziometacarpal Joint Total Joint Arthroplasty. J Funct Biomater 6: 318-327. [Crossref]

42. Kollig E, Weber W, Bieler D, Franke A (2017) Failure of an uncemented thumb carpometacarpal joint ceramic prosthesis. J Hand Surg Eur Vol Jan 1:1753193416688427. doi: 10.1177/1753193416688427. [Crossref]

43. Goorens CK, Van Schaik DE, Goubau JF (2015) Surgical treatment after a failed trapeziectomy: A case report. Chir Main 34: 205-209. [Crossref]

44. Teissier J, Alkar F (2011) Trapeziometacarpal Maia ${ }^{\circledR}$ prosthesis for basal thumb arthritis. A series of 100 prosthesis with a minimum follow-up of 3 years. Chir Main 30(Suppl.1): 77-82.

45. Teissier J (2011) Surgical strategy for revising aseptic loosening of trapezo-metacarpal prosthesis. Chir Main 30(Suppl 1): 106-109.

46. Schmidt I (2014) Thumb CMC total exchange arthroplasty with the ARPE implant Chir Main 33: 295-298. [Crossref]

47. Apard T, Saint-Cast Y (2007) Revision of the ARPE prosthesis by the Jones procedure a study of 6 cases and review of literature. Chir Main 26: 95-102. [Crossref]

48. Hansen TB, Homilius M (2010) Failed total carpometacarpal joint prosthesis of the thumb: results after resection arthroplasty. Scand J Plast Reconstr Surg Hand Surg 44 171-174. [Crossref]

49. Knak J, Hansen TB (2016) Trapeziectomy or revision into a cemented polyethylene cup in failed trapeziometacarpal total joint arthroplasty. J Plast Surg Hand Surg 50: 286-290.

50. Kaszap B, Daecke W, Jung M (2013) Outcome comparision of primary trapeziectomy versus secondary trapeziectomy following failed total trapeziometacarpal joint replacement. J Hand Surg Am 38: 863-871.

51. Lenoir H, Erbland A, Lumens D, Coulet B, Chammas M (2016) Trapeziectomy and ligament reconstruction tendon interposition after failed trapeziometacarpal joint replacement. Hand Surg Rehabil 35: 21-26.

52. De Smet L, Van Meir N, Verhoeven N, Degreef I (2010) Is there still a place for arthrodesis in the surgical treatment of basal joint osteoarthritis of the thumb? Acto Orthop Belg 76: 719-724.

53. Vermeulen GM, Brink SM, Slijper H, Feitz R, Moojen TM, et al. (2014) Trapeziometacarpal arthrodesis or trapeziectomy with ligament reconstruction in primary trapeziometacarpal osteoarthritis: a randomized controlled trial. J Bone Joint Surg Am 96: 726-733.

Copyright: (C2017 Schmidt I. This is an open-access article distributed under the terms of the Creative Commons Attribution License, which permits unrestricted use, distribution, and reproduction in any medium, provided the original author and source are credited. 